\title{
O LABIRINTO RELIGIOSO OCIDENTAL. DA RELIGIÃO À ESPIRITUALIDADE. DO INSTITUCIONAL AO NÃO CONVENCIONAL
}

Deis Siqueira*

\begin{abstract}
Resumo: O texto recupera questões clássicas da Sociologia da Religião, tais como supremacia da sociedade, coesão social, forças morais, "membresia", modernidade racional e intelectualizada, alienação, ilusão, para refletir o labirinto religioso contemporâneo. Este é pensado, sobretudo, a partir da busca por uma religiosidade não convencional, campo religioso pluralista, trânsito, bricolagem, privatização e individualização, espiritualidade e ambientalismo, espiritualidade no contexto organizacional, "empresarização" das igrejas, espiritualização das empresas, destacando uma tendência geral no sentido de "espiritualidade sim, religião não".

Palavras-chave: religião; religiosidade; espiritualidade.
\end{abstract}

\section{Introdução}

Uma problemática antiga dos estudos de religião diz respeito a se a religião seria, ou não, um fenômeno universalmente humano (homo religiosus). Apenas se pode afirmar que todas as civilizações passadas e atuais das quais se dispõe de documentação confiável apresentaram ou apresentam algum tipo de manifestação religiosa, mas isso não nos permite elaborar conclusões universalistas quanto a sociedades antigas sobre as quais pouco se sabe ou quanto a sociedades futuras (James, 1994).

\footnotetext{
* Departamento de Sociologia da Universidade de Brasília (UnB); pesquisadora do Conselho Nacional de Desenvolvimento Científico e Tecnológico (CNPq).
}

Artigo recebido em 18 abr. 2008 e aprovado em 16 jun. 2008. 
Não é demais lembrar que os termos religião e religioso, de matriz latina, são estranhos à linguagem das culturas antigas (excluída a romano-latina) e das culturas não européias. $\mathrm{E}$ as interpretações que se fizeram do termo, historicamente, são muitas: escrúpulo, consciência, exatidão, lealdade; um estilo de comportamento marcado pela rigidez e precisão. A partir de Agostinho (354-430), enfatiza-se a exortação do homem para Deus, articulando-se religio a religando. Estava aberto o caminho para a idéia de ligação baseada na submissão e no amor entre o homem e Deus. Na atualidade, a idéia mais corrente é a de religare (tendo como fonte o termo latino relegere ou religáre), que não significa, necessariamente, religação com um Deus, mas, sim, com a existência, com o cosmos, com as dimensões invisíveis, com o divino, com o misterioso.

No início do século XX, coloca-se uma problemática básica (em termos do que são a origem e as âncoras do conhecimento) da Ciência da Religião: compreender ou explicar a religião e a religiosidade. Posteriormente, Evans-Pritchard escrevia sobre a atitude dos sociólogos e, em particular, dos antropólogos sociais, diante da fé e da prática religiosa, em sua maior parte, como francamente hostil, anti-religiosa. Seus contemporâneos seriam agnósticos e positivistas, apesar de a Antropologia ter surgido a partir dos estudos comparativos da religião. Segundo o autor, esta era tratada como superstição para a qual era necessária uma explicação científica. A maioria dos antropólogos "[...] sustentariam que a fé religiosa é uma ilusão, um curioso fenômeno que logo será extinto e que poderá ser explicado [...]" (Evans-Pritchard, 1986, p. 11). Afinal, a Antropologia teria sido produto de mentes que, com raras exceções, encaravam a religião como inútil, além do fato de esta ter dificultado o caminho do que era considerado como de regeneração racional da humanidade e do progresso.

De fato, concordando com Evans-Pritchard (ibid., p. 18), as leituras feitas por vários clássicos sobre a religião, no século XIX e 
no início do século XX (Comte, Durkheim, Marx, Freud, Weber), foram francamente críticas e desqualificadoras. A frase de Marx (1818-1883) de que a religião é o ópio do povo é a mais conhecida das afirmações, mas tanto ele, quanto outros grandes sociólogos e o pai da psicanálise, Freud (1856-1939), estavam convencidos de que a religião desapareceria com o desenvolvimento da ciência e da racionalidade moderna, postura que já se encontrava no pensamento, por exemplo, de Lucrécio, no século I a.C. Este afirmava que a religião nascia do medo do incontrolável, que sua função seria induzir os homens a realizar até mesmo coisas nefandas e que ela estava destinada a desaparecer.

$\mathrm{Na}$ atualidade, há autores que afirmam que se está diante de uma realidade que estaria apontando para uma possível implosão do próprio conceito de religião (Oro e Steill, 1977), o fim da religião (Giumbelli, 2002). Fala-se ainda de decomposição do religioso. O fato é que se assiste a uma perda crescente de autoridade das instituições religiosas, um processo de desinstitucionalização, de indiferentismo religioso, de carência de "vocação" ou de interesse pelo ingresso em ordens religiosas. Hortal (1993) pensa o processo, no início da década de 1990, em termos de que a religião teria virado artigo de consumo descartável. E uma das questões postas pela Conferência Nacional dos Bispos do Brasil (CNBB) na abertura da revista onde foi publicado o texto de Hortal foi: "O que fazer diante da expansão dos grupos religiosos não católicos?”.

O fato é que a religião e a religiosidade não desapareceram, mas estariam sendo revividas, como nos sugere o título do livro do sociólogo Berger (1996), Rumor de Anjos: a sociedade moderna e a redescoberta do sobrenatural. E os que se declaram "sem religião" são, em sua maioria, crentes sem vínculo institucional, podendo ser, inclusive, confundidos com religiosos, principalmente, por terem crenças próprias, sobretudo do universo cristão (Fernandes, 2006; Novaes, 2005). E este reviver, na atualidade ocidental, aponta para 
questões muito instigantes. Uma das mais evidentes é o processo de transmutação de religião em espiritualidade.

Espiritualidade refere-se, especialmente, a uma questão de natureza pessoal: resposta a aspectos fundamentais da vida, relacionamento com o sagrado ou com o transcendente, o qual pode (ou não) levar ao desenvolvimento de rituais religiosos e à formação de comunidades. Para Hill e Pargament (2003), a espiritualidade está ligada aos aspectos pessoais e subjetivos da experiência religiosa e a uma busca pelo sagrado, processo através do qual as pessoas procuram descobrir e, em alguns casos, transformar aquilo que têm de sagrado em suas vidas.

Este artigo trata de algumas das questões sobre o referido processo. Ou seja, a construção de um campo religioso pluralista marcado por duplicidades e multiplicidades; o crescimento da busca por uma religiosidade não convencional; a "psicologização" da religião; a privatização e individualização típicas da modernidade levadas às últimas conseqüências; a "empresarização" das igrejas e a "espiritualização" das empresas.

Estas reflexões são fruto, sobretudo, de anos de pesquisa que vem sendo desenvolvida no Departamento de Sociologia da Universidade de Brasília (UnB), com o apoio do Conselho Nacional de Desenvolvimento Científico e Tecnológico (CNPq) em torno da Sociologia das Adesões: religiosidades não convencionais. Estas se ancoram na capital federal e entorno. Entretanto, os seus resultados podem ser, em boa medida, generalizáveis, pelos motivos que se seguem.

Uma das etapas desta investigação foi uma pesquisa comparada internacional realizada com quase 4.000 estudantes universitários de 16 universidades em 10 países europeus e americanos (Argentina, Brasil, Colômbia, Uruguai, Alemanha, Áustria, Grã-Bretanha, Itália, Portugal, Estados Unidos) sobre religião e esoterismo (Valle- 
Hollinger, Siqueira e Hollinger, 2002). Confirmou-se a tendência, no Ocidente, da busca por religiosidades não convencionais. No que se refere ao processo de "psicologização" da religião, comprovouse que a maioria dos estudantes teve algumas experiências com as práticas não convencionais ou New Age. Tal processo iniciou-se como pequeno movimento contracultural, na década de 1960, nos Estados Unidos, como uma reação às condições e à organização de vida das sociedades industrializadas. Fez parte de um movimento mais amplo de contestação, incluindo o movimento hippie e o estudantil. $\mathrm{O}$ ano de 1968 é um ano de referência para o movimento contestatório estudantil, que eclodiu na Europa e também na América Latina. As atividades New Age têm se tornado crescentemente populares, particularmente entre as novas gerações e os estratos da população com maior nível de escolaridade, articulando-se à utilização de práticas orientais, de crenças e práticas pré-capitalistas, à ecologia, aos movimentos pacifistas e holísticos (que buscam a unidade), dentre outros. Um número considerável dos estudantes teve um contato bastante próximo com o mercado esotérico.

O padrão de disseminação dessas atividades entre os diferentes países pesquisados não é tão distinto como é o caso da religiosidade e das crenças mágico-esotéricas. Métodos orientais de espiritualidade e cura têm sido praticados mais freqüentemente por estudantes dos países do norte e oeste da Europa. Fora desse continente, esses métodos têm maior grau de disseminação nos centros metropolitanos (como Brasília, Montevidéu e Medellín) do que em cidades menores e mais conservadoras. Os métodos esotéricos que já tinham uma longa tradição nas sociedades ocidentais (curandeirismo, cartomancia) são praticados, mais freqüentemente, pelos estudantes latino-americanos, mas também pelos norte-americanos.

Examinando-se os resultados internacionais das atividades New Age e não convencionais, com os resultados da religiosidade e das crenças mágico-esotéricas, pode-se afirmar que a prática 
esotérica na Europa norte-ocidental tem um caráter bastante secularizado: os métodos espirituais e esotéricos têm sido usados para obter experiências holísticas (emocionais, sensuais, cognitivas) e para explorar a própria personalidade, sem que isso implique, necessariamente, adesão às crenças associadas a tais práticas em seu contexto original. Por sua vez, os métodos espirituais e esotéricos na América Latina e também nos Estados Unidos têm sido vistos mais na sua forma original, isto é, ligados a um cosmo sagrado de entidades espirituais e divinas.

Em outras palavras, os resultados desta pesquisa confirmam o privilégio da capital do Brasil como objeto destes estudos. Ao mesmo tempo em que nela se fazem presentes crenças e práticas mágicas tradicionais da sociedade, o padrão de consumo de práticas New Age e não convencionais é semelhante aos da Europa.

\section{Questões clássicas da Sociologia da Religião}

Supremacia da sociedade, coesão social, forças morais, "membresia" (Comte e Durkheim)

Segundo Comte (1798-1857), o papel central da religião seria integrar o sistema social, consolidar e estabilizar a relação homem-sociedade. Ele destaca a noção de forças morais das crenças religiosas.

Durkheim (1858-1917) centralizou a questão: o que mantém a sociedade unida? As instituições religiosas funcionariam dentro da estrutura da sociedade. As crenças e práticas serviriam como meios culturalmente determinados de manter e regular relações e ajustes humanos, propiciando estabilidade às sociedades.

Durkheim (1989) busca identificar a reciprocidade entre religião e sociedade - religião como um fato social, que tem o poder 
de exercer coação externa sobre os indivíduos. A oração e o rito seriam expressões dessa submissão. A ênfase de sua análise recai sobre o coletivo, a sociedade, a força religiosa. A religião seria algo social e corresponderia a determinadas condições históricas das sociedades. Como estas são as fontes do sagrado, a religiosidade individual seria marcada por movimentos originados nas relações estabelecidas entre as pessoas com a sociedade. Daí que o autor enfatize o aspecto consensual da religião e considere a igreja como o espaço onde as crenças, as práticas religiosas se articulam, formando uma comunidade moral. A sociedade é a alma da religião. Portanto, a concepção desta como submissa à sociedade é vertebral:

A religião deixa de ser inexplicável alucinação qualquer para fundar-se na realidade [...] o fiel não se engana quando acredita na existência de força moral da qual depende e da qual lhe vem o melhor de si mesmo; essa força existe: é a sociedade [...] (Durkheim, 1989, p. 281).

Nesse sentido, pode-se dizer que Durkheim, de alguma maneira, pensa que a sociedade se autodiviniza: “[...] as práticas do culto [...] estreitam realmente os laços que unem o indivíduo à sociedade de que é membro, já que o deus é apenas a expressão figurada da sociedade" (Durkheim, 1989, p. 282).

Resumidamente, há alguns componentes fundamentais para se pensar a religião na concepção durkheimiana. Primeiro, o conjunto de crenças e práticas capazes de aglutinar um número de pessoas, criando, a partir de então, uma solidariedade em virtude de práticas e crenças comuns. Segundo, a separação entre sagrado e profano. Por fim, o aspecto relacional é uma dimensão significativa: a fidelidade do crente à sua igreja constitui-se como um elemento identitário e orientador de conduta. Produz-se uma ética, verificada no comportamento do indivíduo, capaz de vinculá-lo ao grupo religioso. Ou seja, a "membresia" seria um dos elementos fundamentais da religião. Durkheim, assim como Comte, admite 
a importância histórica da religião, mas afirma que esta não teria nenhum lugar importante nas sociedades modernas, fundadas no progresso técnico-científico.

\section{Modernidade racional e intelectualizada (Weber)}

Nas análises de Weber (1864-1920) sobre a sociedade moderna, sobressai o processo de racionalização, a fragmentação das visões de mundo, em que o secular toma o lugar dos deuses e dos profetas. Ele lê a presença de ordens plurais de valores e de éticas competindo entre si, gerando uma situação na qual se tornava cada vez mais difícil, para o homem, encontrar um significado para a vida, cabendo a cada um, cada vez mais, a escolha e a combinação destas. Assim, indica o direcionamento da religião para a vida privada e sugere que a ação religiosa ou magicamente orientada seria produto histórico, como um mecanismo para se viver melhor neste mundo. Afinal, a vida não tem sentido. Esses aspectos da privatização e da nominação (atribuição de sentido) serão centrais na reflexão posterior, desenvolvida, por exemplo, por Berger (1985 e 1996) na década de 1960.

Weber identifica uma tensão constante entre o pensamento religioso e a racionalidade instrumental da ciência, entre o domínio da crença na ciência e o domínio da salvação religiosa. Referindose à crescente intelectualização e racionalização da modernidade, remete ao desencantamento do mundo, afirmando:

[...] significa que sabemos ou acreditamos que, a qualquer instante, poderíamos, bastando que o quiséssemos, provar que não existe, em princípio, nenhum poder misterioso e imprevisível no decurso de nossa vida, ou, em outras palavras, que podemos dominar tudo por meio de cálculo. Isto significa que o mundo foi desencantado. Já não precisamos recorrer aos meios mágicos para dominar os espíritos ou exorcizá-los, como fazia o selvagem que acreditava na existência de 
poderes misteriosos. Podemos recorrer à técnica e ao cálculo. Isto, acima de tudo, é o que significa a intelectualização (Weber, 1992, p. 439).

\section{Alienação, ópio, ilusão (Marx, Engels, Freud)}

Uma das concepções mais usuais sobre religião, na modernidade, é a de Marx, que a considera "falsa consciência" (falsas crenças). Esta seria o ópio do povo, ou seja, uma falsa e ilusória representação do mundo. Para Marx (1976, p. 27), tal como escreveu em 1842, “[...] A religião não vive no céu, mas sim na terra". Ou seja, trata-se de produção humana. “[...] foi o homem quem fez a religião, não foi a religião que fez o homem. Assim, este Estado, esta sociedade, produzem a religião, consciência invertida do mundo [...]" (id., 1976a, p. 79). São inúmeras as citações que são encontradas nos escritos de Marx e Engels (1820-1895), criticando duramente a religião e prevendo seu fim e, inclusive, a necessidade de sua abolição (id., 1976b, 1976c; Engels, 1976).

Freud foi outro clássico que se ancorou em uma perspectiva crítica com relação à religião. Se Marx a batizou como ópio, Freud a batizou como uma ilusão. No conjunto de sua obra sobressaem: Totem e tabu: alguns pontos de concordância entre a vida mental dos selvagens e dos neuróticos (1974), escrita entre 1912 e 1913, e O futuro de uma ilusão (1974), escrita em 1927.

Esse autor destaca as correspondências entre religião e neurose e, sobretudo, entre as semelhanças do pensamento neurótico com as representações dos povos primitivos, porque [...] os atos obsessivos primários desses neuróticos são de um caráter inteiramente mágico [...] Também as fórmulas protetoras das neuroses obsessivas encontram sua contrapartida nas fórmulas da magia (Freud, 1974, p. 110). A neurose obsessiva seria o correlato patológico da formação 
de uma religião. Descreve a neurose como uma religiosidade individual e a religião como uma neurose obsessiva universal.

As idéias religiosas e sua “[...] incontrovertível falta de autenticidade [...] independente, como é, do conhecimento pela razão" (ibid., p. 111) seriam proclamadas como ensinamentos, não seriam frutos do pensamento, mas

[...] ilusões, realizações dos mais antigos, fortes e prementes desejos da humanidade [...] Constitui alívio enorme para a psique individual se os conflitos de sua infância, que surgem do complexo paterno - conflitos que nunca superou inteiramente -, são dela retirados e levados a uma solução universalmente aceita [...] Sua técnica (da religião) consiste em depreciar o valor da vida e deformar o quadro do mundo real de maneira delirante - maneira que pressupõe uma intimidação da inteligência (ibid., p. 116 e p. 41).

Freud conclui que Deus não seria mais do que um pai glorificado e, portanto, criação humana, e que "[...] o afastamento da religião está fadado a ocorrer com a fatal inevitabilidade de um processo de crescimento, e nos encontramos exatamente nesta junção, no meio dessa fase de desenvolvimento" (ibid., p. 57). De qualquer forma, ele reconhece as funções da religião. Fazendo a analogia entre esta e a neurose obsessiva, pensa que os devotos estariam salvaguardados do risco de certas enfermidades neuróticas, pois a aceitação da neurose universal lhes pouparia o trabalho de elaborar uma neurose pessoal. Ademais, “[...] Contribuiu muito para domar os instintos associais" (ibid., p. 50).

Porém, a longo prazo, segundo esse autor, nada poderia resistir à razão, à experiência: "[...] a contradição que a religião oferece a ambas é palpável demais" (ibid., p. 68). E a ciência já nos teria dado prova suficiente de que ela não é uma ilusão. “[...] Não, nossa ciência não é uma ilusão. Ilusão seria imaginar que aquilo que a ciência não nos pode dar, podemos conseguir em outro lugar." (ibid., p. 71) 


\section{A labiríntica atualidade ocidental: trânsito, pluralidade, bricolagem, espiritualidade no contexto organizacional}

\section{A busca por uma religiosidade não convencional}

Identifica-se, na atualidade ocidental, um crescimento da busca por novas religiosidades, religiosidades não convencionais ou nova consciência religiosa. Também no Japão se destaca, no pósSegunda Guerra Mundial, esse crescimento.

Nesse sentido, encontram-se na literatura específica, dentre outras, expressões como campo religioso ampliado; religião difusa; religiosidade ou identidade religiosa flexível-flutuante; espaço religioso novo ou novas formas do sagrado na sociedade atual e nova sensibilidade místico-esotérica; sacralidade não religiosa e sacralização das relações individuais de transcendência; nova religiosidade sincrética, esotérica-holista da New Age, Novos Movimentos Religiosos ou novas formas da religião; nebulosa místico-esotérica e crédulos difusos; nebulosa heterodoxa; religiões seculares; religiosidade inorgânica; nebulosa polivalente da Nova Era; diversidade de identidades; diversidade nas formas de adesão; orientalização do Ocidente. Recentemente, Hervieu-Léger (2005) fala do paradoxo religioso das sociedades seculares, nas quais a religião se torna, cada vez mais, uma escolha ajeitada e complexa em que pode haver um "pegue e largue" ou a reconstrução de valores e práticas religiosas por parte das pessoas.

Também na América Latina tem crescido uma religiosidade difusa que inclui o movimento New Age, mas não se reduz a ele. Algumas das técnicas que assim são consideradas, tais como o curandeirismo, a cartomancia e a astrologia, pertencem ao repertório tradicional de cura e de conselhos práticos, dão-se às margens do institucional e têm sido "redescobertas" pelo movimento que se originou nos centros urbanos de sociedades mais desenvolvidas; por isso, elas tendem a ganhar popularidade nesses países, também. 
Esse movimento inclui tanto aspectos triviais, como os horóscopos, quanto uma sensibilidade religiosa abrangente, holística (presença do sagrado como princípio unificador). Partese de uma perspectiva eclética, ecumênica, além de se encontrarem afinidades, segundo os adeptos de religiosidades não convencionais, com referenciais científicos mais recentes, tais como a energia e o salto quântico. Podem-se encontrar, por exemplo, grupos religiosos que se autodenominam alquimistas: afirmam estar trabalhando com transmutação de energias densas e pesadas, transmutando energia magnética em energia eletrônica (Siqueira, 2003; Siqueira e Lima, 2003).

Estaríamos vivendo um processo de "reencantamento" do mundo e uma reabilitação cultural da magia, sobretudo, por seu potencial psicoterapêutico (Noth, 1996). Os limites que separam religião de magia estariam desaparecendo, e a religião não mais poderia ser identificada com igreja. Ademais, tem se dado uma recuperação de práticas, de crenças, de valores, místicos e esotéricos, os quais seriam experiências vivenciais, misteriosas. Tanto assim que, nas investigações que começaram a ser desenvolvidas, em 1994, pelo grupo de pesquisa do Departamento de Sociologia da UnB, o conceito instrumental que foi utilizado para fazer referência aos grupos de buscadores das novas religiosidades foi, durante um bom tempo, o de "grupo místico-esotérico". Fugindo da denominação de Igreja, autodenominam-se Associação, Cavaleiros, Centro, Cidade, Collegium, Espaço, Fé, Filhos, Fraternidade, Fraternidade Eclética, Forças Mentais, Fundação, Grupo, Instituto, Legião, Loja, Movimento, Ordem, Ponte, Sociedade, Templo.

Os elementos dessa busca podem ser aglutinados em torno de práticas e de crenças religiosas, mágico-esotéricas e New Age. Suas crenças e valores principais são: carma e reencarnação; visibilidade do eu interior, eu superior, eu maior, eu crístico ou eu próprio; o 
mundo é uma ilusão: anular o ego e desapegar-se; a divinização do indivíduo; auto-aperfeiçoamento.

Para a maioria dos adeptos das religiosidades não convencionais, a postura é de transformação interior do indivíduo (autoconhecimento, auto-aperfeiçoamento e desenvolvimento espiritual) e certo estado de ser e de se relacionar com o mundo (a presença do divino em tudo e em todos e, como conseqüência, negação das separações e dualidades, tais como natural-sobrenatural, sagrado-profano, racionalidade-sensibilidade). $\mathrm{O}$ religioso articular-se-ia a conteúdos aparentemente profanos de saúde, dietéticos, bem-estar corporal, vitalidade, desenvolvimento das potencialidades pessoais, consciência planetária, harmonia com a natureza e com o cosmos, o que caracterizaria um novo estilo de vida e um movimento de "psicologização" das religiões: terapias e práticas não convencionais, assim como a literatura de auto-ajuda (Siqueira, 2003; Siqueira e Lima, 2003).

A espiritualidade ou caminho espiritual se refere não apenas à reestruturação do campo propriamente religioso, mas se remete a campos como a Psicologia e a Medicina, em um movimento em que novos significados, autoridades, competências se encontram em processo de legitimação.

Um dos elementos mais significativos dos buscadores dessa religiosidade não convencional é o trânsito pelos grupos, por religiões, por práticas não convencionais, alternativas ou $\mathrm{New}$ Age. Busca-se uma religiosidade antiinstitucional, anti-hierárquica, anticlerical. E muitos, depois de circularem, acabam vivenciando uma religiosidade por conta própria, fazendo uma bricolagem (combinação criativa) de elementos, práticas, crenças originadas em diferentes fontes, não se sentindo, no geral, membros de nenhuma. Identifica-se uma grande circulação de valores, de significados e de mestres, que são referenciados entre os diversos grupos de adeptos. 
Trata-se, portanto, de um discurso ecumênico, centrado em torno da busca de uma unidade com Deus, das religiões e da humanidade.

Nesse contexto, os templos, os ritos, os dogmas vêm perdendo importância e a devoção teria caráter complementar, porque a ênfase deve estar posta na ação, no cotidiano. As fronteiras entre o profano e o sagrado se diluem. Alguns minutos em um congestionamento podem ser um tempo de meditação.

$\mathrm{Na}$ verdade, religiões mais antigas do que o cristianismo, por exemplo, os budismos, estão sendo vivenciadas como novas religiosidades ou religiosidades não convencionais no Ocidente.

Referindo-se ao budismo, Soares (2004, p. 139) afirma que o mesmo

[...] é visto como componente do cosmos sagrado da atualidade. Os principais aspectos que contribuem para essa afirmação são: o exercício a nível individual, privado, reconhecido como uma "psicologia budista"; o "pragmatismo" deste tipo de religião, fundamentada em regras úteis para o mundo; e a relação com outras pessoas e com o universo, que enaltece uma "cosmovisão holística".

Mas a expectativa mais evidente é diferenciar-se das religiões ocidentais tradicionais (cristãs), identificadas por esses buscadores, em geral, como excessivamente clericais, doutrinárias, hierárquicas, dogmáticas.

Outro elemento importante diz respeito ao individualismo levado às últimas conseqüências nesse processo de privatização e construção da própria religiosidade. Nesse sentido, afirma o grupo de pesquisadores da UnB sobre os adeptos de religiosidades não convencionais (Siqueira, Bandeira, Ribeiro et al., 2000, p. 355):

O indivíduo com seu Ego, com seu Eu Superior e com sua subjetividade instala-se no centro do mundo. O paradoxo e o movimento ambivalente para os freqüentadores e, sobretudo, 
para as "lideranças" estão postos. Isto porque, apesar do discurso coerente de ambos, ancorado em uma rede de significados também coerente, se articula [...] aos Egos que se expandem e as "lideranças" narcísicas florescem, seja a partir de um autoconhecimento, seja a partir do reconhecimento do grupo: mais horas acumuladas de meditação, maior autocentramento, maior domínio dos mantras e técnicas ritualísticas, enfim: maior iluminação, espiritualização, transcendência, ou mesmo "budização".

Portanto, outra característica da nova religiosidade ou religiosidade não convencional seria um individualismo exacerbado. Afinal, os esforços se concentram em torno do indivíduo. Práticas tradicionais, voltadas às outras pessoas, ao Outro, tais como piedade, caridade, generosidade, são, em boa medida, passadas para segundo plano. A tendência se dá na direção da substituição da salvação (pósmorte) pelo "aqui e agora".

Registre-se que a Teologia da Libertação tem uma vertente mais recente, de caráter crítico, que tenta afastar a influência da $\mathrm{New}$ Age para fora do catolicismo. Boff e Frei Betto continuam a buscar, com ela, interlocuções. Segundo Camurça (1998, p. 22), “[...] a última produção teológica de Boff e Betto estaria inspirando a ampliação dos atuais paradigmas de vivência do catolicismo brasileiro ao incorporar uma dimensão holística: aquela da meditação oriental, da terapêutica e da ecologia". Registre-se que o frade dominicano Betto (2001) escreveu, há poucos anos, Física, cosmologia, teologia e espiritualidade, onde tenta rearticular a fé e a espiritualidade cristãs com algumas cosmovisões atuais, provenientes de teorias físicas sobre o universo.

Campo religioso: pluralismo, duplicidades, multiplicidades

Pesquisas realizadas por Negrão (2008) na cidade de São Paulo confirmam a continuidade do processo de esvaziamento do catolicismo e do crescimento protestante, especialmente pentecostal ${ }^{2}$ 
e indicam, ainda, caminhos percorridos por agentes religiosamente mutantes, crenças, pertencimentos e vivências duplas, múltiplas ou ambivalentes no que diz respeito ao vínculo institucional ou à tradição religiosa.

As principais doutrinas e instituições eclesiásticas seguem sendo fonte de símbolos, de crenças, mas o aspecto que se destaca é a dimensão da subjetividade na construção do religioso e a crescente individualização da religiosidade. $\mathrm{O}$ indivíduo seleciona o que faz com que se sinta bem, que responda às suas dúvidas ou mesmo que lhe convenha em termos de sua condição socioeconômica, nível de instrução, necessidades particulares. Portanto, os resultados de mais de uma década de pesquisas realizadas no Departamento de Sociologia da UnB sobre religiosidades não convencionais e seus adeptos são confirmados pelas investigações desenvolvidas por Negrão em torno do campo religioso brasileiro. Em outras palavras: adesões não rápidas ou definitivas a uma determinada "membresia", mas, sim, vivências dúplices ou múltiplas do simbólico e abertura para futuras incursões em outros universos simbólicos (além da existência dos totalmente indecisos porque todas as religiões são boas, são caminhos alternativos que conduzem ao mesmo Deus, e dos que afirmam "a minha religião eu mesmo faço").

A dinâmica do campo religioso brasileiro caracteriza-se, na atualidade, segundo o autor (com exceção dos protestantes), por: distanciamento dos adeptos religiosos da vivência eclesial e dos sacramentos; desqualificação das instituições e inexistência de habitus religiosos; tendência dos mutantes a recusar uma "membresia" definida e a se valerem do que lhes parece mais adequado ou conveniente (sendo a Igreja, no geral, considerada autoritária e dogmática) em direção a uma vivência religiosa individualizada e solitária; experiência simultânea de crenças e de práticas ou de religiosidades pessoais, as quais agregam valores, práticas, crenças de tradições religiosas diversas; recuperação da magia e exaltação 
dos sentidos, que colocam o homem em contato com o cosmos; estética que se comunica com as emoções (harmonização com a natureza, equilíbrio emocional, saúde); dimensão de auto-ajuda (terapias que recuperam energias e auxiliam no cotidiano).

De qualquer forma, vale ressaltar que, segundo Negrão (ibid.), esse processo de construção de cenários religiosos individualizados (seleção de crenças e rituais de diversas procedências) se dá com maior intensidade com os adeptos de religiões orientais e de esoterismo (budistas, hinduístas, adeptos de novas religiões japonesas), confirmando as observações anteriores. Ele destaca os protestantes como a exceção a esse movimento. É preciso lembrar, entretanto, que a efervescência religiosa é tão grande que, mesmo dentro das religiões tradicionais, surgem importantes movimentos religiosos. Os exemplos mais evidentes destes, na atualidade, são as igrejas neopentecostais e a Renovação Carismática Católica (RCC). Ademais, o modelo protestante pentecostal e a RCC (a qual importa ou herda formas de expressão do pentecostalismo) são um bom exemplo do processo de assemelhação entre o catolicismo e o protestantismo. Há um novo tipo de católico, com várias semelhanças com os pentecostais, tanto no que concerne às regras de comportamento no cotidiano, quanto nas celebrações. Em ambos, são centrais o Espírito Santo e seus dons (cura, falar línguas desconhecidas), bem como a característica catártica dos cultos.

A Igreja Universal do Reino de Deus(IURD)éum bom exemplo de diluição de fronteiras religiosas: há uma guerra, declarada por ela, centrada no controle do espaço simbólico-religioso. A demonização das demais (católica, cultos afro-brasileiros, adventistas do sétimo dia, testemunhas de Jeová e mesmo movimentos como a New Age) é um dos eixos dessa guerra (Benedito, 2003), mas a "guerra santa" foi deflagrada, sobretudo, contra os cultos afro-brasileiros (usuários da feitiçaria). Entretanto, ocorre, ambígua e simultaneamente, "[...] uma simbiose ou hibridização ritualística com seus inimigos [...] os 
universais aplicam em suas práticas muitos dos rituais e símbolos herdados dos afro-brasileiros" (ibid., p. 196-197), em particular, os artefatos mágicos (Mariano, 1999). Além disso, apropriam-se de parte da hierarquia eclesiástica da Igreja Católica - os bispos, ainda que não se exija dos mesmos uma formação em teologia.

Entre as religiões evangélicas, também ocorre um grande trânsito de religiosos. Assim, na esfera religiosa, transita-se, cada vez mais, por caminhos diversos, fragmentados, plurais, típicos da modernidade, ainda que esse trânsito esteja, paradoxalmente, apoiado na busca de uma dimensão holística ou totalizante de ser e de estar no mundo, a partir, sobretudo, do esforço individual: religião como parte cada vez maior da vida privada.

Não é demais lembrar que Durkheim(1989, p. 78-79), ancorado na religião em sua perspectiva social, de alguma maneira, anteviu, desejoso, a possibilidade de uma religiosidade individualizada. Ele se perguntou, em 1912, em que medida as religiões individuais

[...] não são chamadas a se tornarem a forma eminente da vida religiosa e se não virá um dia em que não haverá outro culto senão aquele que cada um fará livremente no seu íntimo [...] mas são especulações sobre o futuro [...] Restam as aspirações contemporâneas a uma religião que consistiria toda inteira em estados interiores e subjetivos e que seria livremente construída por cada um de nós.

\section{Espiritualidade sim, religião não}

Outro aspecto indicativo das articulações existentes no labirinto religioso ocidental diz respeito aos trânsitos existentes entre espiritualidade e contexto de trabalho, assim como ambientalismo\&natureza\&novos movimentos alternativos. Em ambos os casos, tende-se a valorizar a espiritualidade, negando-se a religião. 
No Ocidente, o cosmos sagrado atual se aproxima bastante do ideal de Durkheim já citado, pois há aberturas para temas, práticas, crenças heterogêneas do religioso e uma ligação com o cosmosnatureza privilegiada. Assim, a espiritualidade se aproxima dos novos ambientalistas, na medida em que estes também apostam na universalidade de suas questões. O novo ambientalismo, segundo McCormick (1992), parte de uma concepção mais sofisticada da relação do homem com a biosfera, se comparado com o ambientalismo, o qual se ancora no equilíbrio entre aquele e seus ambientes.

A partir da década de 1970, cresceu a formação de espaços alternativos para práticas ligadas à saúde, à educação, à divisão de trabalho, à organização social: locais de crítica ao consumismo e ao capitalismo hegemônico, bem como, em âmbito geral, articulados à espiritualidade, porque, como sugere Guatarri (1990), devese partir de uma postura ético-política que articule três registros ecológicos: meio ambiente, relações sociais e subjetividade humana. Os movimentos contraculturais iniciados na década de 1950 (beat, beatnik) e, posteriormente, o hippie, são os precursores dos movimentos alternativos atuais. Neles se discutia a "redução dos níveis de consumo, adotando-se estilos de vida mais simples ou naturais" (Ehlers, 1996).

Assim, na atualidade, fala-se em unidade com a natureza, neomisticismo ecológico, espiritualidade intrínseca ao trabalho ecológico, pois, como o planeta é uma rede em que todos estão conectados, trata-se de uma relação espiritualizada com a natureza, a partir da síntese corpo-espírito-natureza, síntese que incorporaria o corpo e o espírito graças à energia que confere à natureza, "[...] qualidades que a humanizam, espiritualizando-a" (Soares, 1994, p. 193).

Segundo Braun (2001, p. 33), a ecologia profunda concebe os indivíduos como parte de um todo, organicamente articulado. Essa 
visão transcenderia a visão materialista, incorporando "a questão vibracional da espiritualidade".

Holmgren (2002, p. 3), por sua vez, afirma que as lentes do pensamento sistêmico e da ecologia permitem identificar

[...] a magia nas perspectivas e tradições espirituais. O mesmo processo tem acontecido no campo da psicologia, especialmente a psicologia de Jung. Muitos pensadores e escritores têm sugerido que os mais progressivos aspectos da ciência têm se movido por meio de uma união com aspectos universais da crença espiritual.

Ainda segundo esse autor, a articulação entre crescimento da espiritualidade e bases ecológicas pode contribuir para a união de ciência e espiritualidade. O livro Fundamentos filosóficos do movimento ecológico, organizado por Unger (1991), reúne vários artigos que tratam das sabedorias espirituais, da pós-materialidade, da espiritualidade como possibilidade de uma nova ética, de sua relação com a ecologia como um assunto político e da percepção espiritualizada como uma busca inerente da condição humana.

Ainda são inúmeros os locais ou territórios que têm sido destacados por sua "mística" devido à energia particular da natureza e têm atraído muitos buscadores de um novo estilo de vida e de uma nova religiosidade (Medrado, 2008; Lima, 2003).

O crescente movimento de recuperação da religiosidade, ancorada em críticas à religião em sua dimensão institucional, também pode ser confirmado pelo crescente interesse pela espiritualidade no contexto do trabalho (organizacional).

No livro Igreja aos domingos, trabalho às segundas: o desafio da fusão de valores cristãos com a vida dos negócios, dois pesquisadores norte-americanos, Nash e McLennan (2003), partindo do impasse gerado pelo vácuo de referência baseada na fé cristã e em uma investigação realizada com empresas e com o 
clero, analisam a incapacidade da Igreja para lidar com o mundo do trabalho, resultando em uma crescente busca por orientações religiosas alternativas - "tudo em torno da espiritualidade" -, em detrimento das práticas religiosas tradicionais.

Tais orientações religiosas alternativas preenchem a lacuna, negociam melhor religiosidade e economia e oferecem opções bem variadas de acesso - gurus, técnicas, programas gerenciais de conforto. Isso tudo não estaria mudando apenas os negócios, mas a própria religião norte-americana (Siqueira, 2003a).

De fato, identifica-se, no ambiente organizacional, uma busca progressiva por maior sentido no trabalho: tendência a transpassar os objetivos pessoais e aumento da associação entre religião, espiritualidade e negócios. A ênfase, porém, tem sido posta na espiritualidade no contexto do trabalho, isto é, construção ou reconstrução de orientações, valores, práticas que não estariam associados ou representados em termos de religião ou mesmo de religiosidade, mas de espiritualidade.

Para Cavanagh (1999), as empresas têm adotado cada vez mais uma axiologia transcendental, ligada a valores como paz interior, verdade, respeito, honestidade. Trata-se de uma busca crescente por significado, equilíbrio, humanização da organização, ambiente não mais centrado no controle, na hierarquia, no individualismo, na obediência, mas, antes, em maior desenvolvimento pessoal, na utilização da intuição, na valorização da criatividade, humanização e auto-realização no trabalho, maior integração da empresa com a sociedade.

Outra razão que ampara a proliferação da perspectiva da espiritualidade no trabalho, segundo Berthouzoz (2002), referese à crença na reciprocidade de práticas de negócios mais éticas e humanas como uma pré-condição para o estabelecimento de economias de mercado mais efetivas. 
Para vários autores, como é o caso de Pauchant (2002), a espiritualidade no contexto do trabalho não está ligada a um sistema religioso, nem mesmo a uma ritualística organizada ou a um proselitismo nas organizações. Por esse motivo, não envolve rituais, doutrinas ou crenças religiosas institucionalizadas (ainda que carregue valores comuns à maioria das tradições religiosas). Para Nash e McLennan (2003), ela oferece empowerment, via "picos de experiência", "fluxo", quadro transformacional de consciência, bem-estar emocional, novas habilidades cognitivas.

Espiritualidade no trabalho refere-se, ainda, à valorização de um axioma o qual promove a experiência de transcendência por meio dos processos de trabalho, facilitando o senso de conexão com os colegas, com a empresa, com a sociedade e com o transcendente, por meio da valorização de sentimentos de totalidade, alegria, direção, significado e sentido com outros e com o transcendente (King, 1997; Giacalone e Jurkiewicz, 2003). Ou seja, espiritualidade no trabalho significa ter um claro sentido no trabalho e legitimá-lo por meio do suporte social e do compartilhamento de valores com outros colegas, possibilitando a construção de uma comunidade organizacional em que se pode superar o senso individual e permitindo significado e satisfação maiores (Fox, 1994; Cavanagh, 1999; Ashar e LaneMaher, 2004).

De acordo com muitos autores, tais como Ashforth e Pratt (2003), a prática religiosa ou espiritual já é bastante comum em várias empresas do mundo ocidental. São exemplos: Banco Mundial, Monsanto, Taco Bell e Pizza Hut. Outras grandes organizações, como Xerox, Mary Kay Cosmetics, Exxon, Harley-Davidson, Boeing, Sun Microsystems, Timberland, Wal-Mart, têm encorajado a integração da espiritualidade à sua gestão organizacional (Pauchant, 2002; Mitroff e Denton, 1999; Bell e Taylor, 2004; Kinjerski, 2004). Nash e McLennan (2003) também informam sobre tais práticas em 
empresas, como a leitura da Torá por judeus e não-judeus, cânticos budistas, cultos beneditinos online para "buscadores não afiliados".

A companhia americana de aviação Southwest Airlines (SWA) tem sido um exemplo bastante explorado. Segundo vários estudos, nela há uma integração de valores espirituais ao contexto organizacional, sobretudo no que tange à gestão de pessoas (Milliman, Ferguson, Trickett et al., 1999; Mitroff e Denton, 1999; Milliman, Czaplewiski e Ferguson, 2003; Kinjerski, 2004). Nessa empresa, comprometimento emocional, empowerment, flexibilidade, participação nas decisões, compartilhamento de idéias e ética no trabalho estão enraizados na cultura e na prática organizacionais. A cultura aí estabelecida tem promovido uma grande liberdade para o humor e a diversão durante o trabalho, cujo objetivo é a promoção de um ambiente desafiador. Para Csikszentmihalyi (1991), esse seria um ambiente propício para o que denominou como o estado de flow: estado em que o trabalhador está no controle de suas ações, o que possibilita um envolvimento intenso com os objetivos do trabalho.

A privatização-individualização da religião parece ter sido exacerbada nas últimas décadas. Tanto assim, que Nash e McLennan afirmam que o auto-empowerment foi, há muito, negligenciado pelas igrejas e que os homens de negócios investigados expressaram desconexão entre os cultos dominicais e as atividades cotidianas, "descrevendo uma sensação de viver em dois mundos que jamais se tocam" (Nash e McLennan, 2003, p. 21).

Ao se centrar em torno da espiritualidade, a qual não se confundiria com religião, esta e seus correspondentes dogmas, crenças, ações, "membresia" recaem sobre o indivíduo e apenas sobre este. Diz respeito à privacidade dos trabalhadores enquanto fora da organização. Todavia, espiritualidade transcende o indivíduo e o remete, sobretudo, a um conjunto de valores, ações e práticas ligados ao coletivo. Trata-se, portanto, de uma tentativa de se reconectar individualmente ao mundo (Mitroff e Denton, 1999). 
Essa utilização da espiritualidade no contexto de trabalho estaria em sintonia com o movimento de valorização e de humanização das organizações. $\mathrm{O}$ aspecto espiritual na gestão das organizações tem sido reafirmado em termos de vantagens, não apenas de natureza financeira, mas, igualmente, de natureza coletiva e social. Aponta-se, sobretudo, para ganhos de satisfação no trabalho, maior comprometimento, maior vinculação à organização a partir de um trabalho com sentido claro, comparativamente a outras organizações onde essa dimensão não está presente.

\section{“Empresarização” das igrejas e espiritualização das empresas}

O declínio da importância das instituições religiosas cristãs e de alguns de seus valores característicos, tais como tradição, conformidade, benevolência, segurança, segundo Schwartz e Huismans (1995), contribui, em termos cotidianos, para que as pessoas abandonem ou secularizem muitos de seus valores, aspirações e motivações. Tal ambiente crescentemente anômico, com perdas importantes de sentido e de significado, têm, segundo Pauchant (2002), acarretado sérios problemas, como estresse, depressão, aumento da dependência química, dentre outros.

Embora, arigor, sejam reconhecidos porseus aspectos sagrados, em contraste com os valores profanos, mundanos, secularizados das empresas assentadas no mercado e na obtenção do lucro financeiro, os sistemas religiosos tradicionais vêm se transformando a fim de competir com outros sistemas de significação existencial (Berger, 1985), tornando-se menos "sacralizados". Essa transição constante entre o sagrado e o profano das instituições religiosas faz com que a religião seja enxergada como uma mercadoria a ser negociada a partir da demanda dos fiéis (Guerra, 2003). As igrejas protestantes neopentecostais são os maiores exemplos dessa transição. No 
Brasil, denominações recentes, como a IURD, Renascer em Cristo, Sara Nossa Terra, caracterizam-se por uma hierarquia rígida, uma liderança carismática e o estímulo ao crescimento quantitativo das igrejas (conversão de fiéis, maior arrecadação, entre outros) (Siepierski, 2001; Silva, 2004), características próprias de grandes empresas comerciais.

Marcado por um forte vínculo à contemporaneidade globalizada, o discurso neopentecostal sobrepõe o modelo quietista de vida e incorpora uma nova axiologia aos fiéis, cuja máxima é ter direito a todas as vantagens que o mundo pode oferecer, ainda em vida, e rapidamente! No Brasil, a Igreja Renascer em Cristo, por exemplo, ancora-se em um modelo característico de um empreendimento secular, em que o discurso é voltado para a classe média e para os jovens, ao mesmo tempo em que combina uma "estética" com elementos da indústria do entretenimento e da comunicação de massa (Siepierski, 2001). Fonseca (2003) lembra que, para muitos analistas, a utilização da mídia por religiosos seria um dos principais reflexos da "mercantilização da fé", já que se torna um espaço importante de veiculação de propaganda e de venda.

A IURD, inclusive, criou um clima de opinião que representa os pentecostais como um bloco e, em alguns casos, o conjunto dos evangélicos brasileiros (Bonfatti, 2000; Burity, 2003). Para essa igreja, a religião pode ser considerada "como uma mercadoria, estabelecendo uma estrutura transnacional para viabilizar da melhor forma possível a exposição e a expansão de seu produto. A 'Evangelização da Mídia' é parte central do ser/fazer da igreja” (Fonseca, 2003, p. 49).

Para Silva (2004), no ambiente das organizações religiosas observam-se, atualmente, características próprias das mudanças sociais e laborais de empresas não religiosas, como maior flexibilidade na produção, variabilidade de competências, carga 
maior de trabalho, decisões cada vez mais rápidas e, principalmente, uma produtividade cada vez maior, seja ela simbólica ou real.

\section{Conclusões}

A religiosidade ou busca de conexão com o transcendental, misterioso, numinoso, sagrado, parece ter sido bastante constante na história conhecida da humanidade. Tanto assim que os clássicos, tais como Comte, Durkheim, Weber, Marx, Freud, reconheceram a importância histórica da religião ou das crenças religiosas.

Weber admitiu que ficaria cada vez mais difícil, para as pessoas, encontrar um significado para a vida diante do desencantamento do mundo, mas ele e os demais clássicos foram bastante críticos da religião e da religiosidade. Freud se remete a elas como neurose. E também apostaram em seu fim na modernidade, caracterizada pelo processo de racionalização, intelectualização, desenvolvimento da ciência, de "tomada de consciência", do cálculo. Afinal, aquela seria ilusão, ópio, alienação.

Ainda que Weber, Freud e também Berger se refiram ao processo de privatização da religião, sua dimensão coletiva\&social\& institucional foi sempre privilegiada: supremacia da sociedade; fato social; religião como integradora do sistema social, estabilizadora das relações homem-sociedade; reciprocidade entre religião e sociedade; coação externa, coesão social, forças morais; fidelidade do crente, "membresia". Haveria, além disso, uma correspondência entre ela e as condições históricas das sociedades, bem como um aspecto consensual entre religião e igreja, em que as crenças e práticas religiosas se articulam, formando uma comunidade moral. Em que sentido nos auxilia esse princípio, associado, por sua vez, ao da "membresia", em um contexto de pluralidade, dualidade, multiplicidade, individualização religiosa, e que é caracterizado, no 
máximo, por adesão? E o que dizer da polaridade sagrado/profano em uma realidade que tende a romper essas fronteiras?

Por um lado, nos últimos séculos, no Ocidente, essas sociedades teriam sido marcadas pelo movimento de desencantamento do mundo (eliminação da magia) e de secularização. De fato, o processo de secularização segue seu curso e deve ser entendido como declínio da religião como potência-instituição, subtração do status religioso, separação das esferas da vida social e, logo, afastamento do Estado e da religião (Pierucci, 1998).

Por outro lado, tem-se assistido no Ocidente, nas últimas décadas, a significativas mudanças no campo religioso, marcadas, de fato, pela perda de espaço das instituições religiosas, ou seja, "secundarização" ou mesmo negação da religião (movimento anticlerical, antidogmático, anti-hierárquico), e, simultaneamente, à valorização da espiritualidade.

Um dos elementos mais significativos desse movimento é o incremento da busca por religiosidades não convencionais, sobretudo, por parte dos estratos mais privilegiados da sociedade, também em níveis de escolaridade. Em que medida se sustenta a leitura de religião como alienação, ópio, ilusão?

Aquelas se caracterizam pelo "centramento" em torno do autoconhecimento, do auto-aperfeiçoamento, do desenvolvimento da espiritualidade. Associam-se, por sua vez, à construção de um "novo estilo de vida", a um movimento de "psicologização" da religião (literatura de auto-ajuda, práticas e terapias não convencionais, $\mathrm{New}$ Age, orientalização do Ocidente), ainda que incorporem conceitos, valores, práticas das religiões tradicionais.

Não se trata, porém, apenas de adesão às religiosidades não convencionais, pois também se identifica, no campo religioso mais amplo, uma tendência à recusa do institucional, do sacerdotal, de 
dogmas e de exclusivismos impostos como verdade. Ou seja, a religião continua sendo valorizada, mas a tendência se constrói no sentido do fortalecimento da privatização: individualização, duplicidade e multiplicidade religiosa, perda de autoridade institucional, trânsito de religiosos, de crenças, de práticas (mesmo entre os evangélicos). Trata-se de um movimento sui generis: busca daquilo que faz mais sentido dentre as opções disponíveis de atribuição de sentido, função primordial das religiões. Assiste-se à edificação de variados construtos não convencionais, alternativos às religiões tradicionais, destacando-se, no processo, filosofias ancoradas na orientação de comportamentos, condutas individuais, não na verdade revelada e dogmática.

Weber afirmou que o secular tomaria o lugar de deuses e profetas. O que se observa é uma retomada ou, pelo menos, um processo de maior visibilidade social das crenças místico-esotéricas e simultânea tendência à privatização da religião. $\mathrm{O}$ secular não toma aquele lugar, mas a tendência parece que se dá no sentido de seu encantamento (magia) e os deuses, os profetas, os dogmas, as verdades reveladas se secularizam cada vez mais (consumo, verdades não exclusivas, bricolagem, escolhas racionais e intelectualizadas a partir das necessidades e particularidades de cada um).

Essa atitude religiosa pode ser considerada, por vários motivos, como pós-moderna, até porque parece que se assiste ao movimento de individualização, possibilitado pela modernidade, levado às últimas conseqüências. Em que medida ela também pode ser lida como um reencontro com os tempos primevos? Porque, assim como afirma Negrão (2008), se trata de um retorno à situação de autoconsumo, o qual, segundo Bourdieu (1974), teria precedido o monopólio sacerdotal - plena constituição do campo religioso.

A expansãoneopentecostal, por sua vez, também parece indicar um novo ambiente sociorreligioso em que o direito a uma vida com 
abundância material, o bem-estar aqui e agora, vem substituindo, em boa medida, o tradicional lugar de ascetismo, de submissão a Deus e de "salvação" pós-morte. Não deixa de ser uma inversão de um dos princípios básicos cristãos tradicionais, o salvacionista. Isso posto, como avançar a reflexão em torno dessa religiosidade contemporânea, não mais tipicamente religiões de salvação (vida pós-morte), e crescentemente ancorada no "aqui e agora" (inclusive entre os neopentecostais - Teologia da Prosperidade)? Identificamse elementos que permitem uma reabertura da discussão do religioso como parte da "essência" humana (James, 1994), mesmo que se esteja apoiado na certeza de que Deus é uma criação humana e, mais, de que Deus nasceu mulher (Rodríguez, 2000)?

Outro elemento-chave do movimento mais amplo é a articulação da espiritualidade com o ambientalismo e a valorização da espiritualidade no contexto do trabalho. Neste último caso, estáse diante de um deslocamento em que a religião diria respeito ao indivíduo-privado, por excelência. Circunscreve-se a noção do coletivo social à de coletivo organizacional e se dá um retorno da religião, agora pensada apenas como espiritualidade (questões de natureza pessoal, da vida, de significado e de relacionamento entre o sagrado e o transcendente). Incorporam-se esses valores ao contexto de trabalho e, simultaneamente, os conflitos usuais decorrentes de diferentes "membresias" ou adesões religiosas (crenças, dogmas) são dele excluídos.

Não se trata, portanto, de religião, já que esta seria incongruente com o mundo empresarial (uso de dogmas) e, sobretudo, pela suposta falta de relação daquela com os problemas complexos e concretos do mundo atual. Tenta-se, assim, recuperar, em boa medida, a moralidade das religiões tradicionais no ambiente organizacional, agora rebatizadas: totalidade, conectividade, equilíbrio. Assim, movimento, por um lado, de "empresarização" das instituições religiosas e, por outro, de espiritualização das empresas. 
Freud (1974) se perguntou onde residiria a força interior das doutrinas e a que deveriam sua eficácia, já que estas são independentes do reconhecimento pela razão. De qualquer forma, adianta, em $O$ mal-estar da civilização (p. 103), a possibilidade futura de escolha religiosa. Ele afirmou, em 1930:

A felicidade [...] Não existe uma regra de ouro que se aplique a todos: todo homem tem de descobrir por si mesmo de que modo específico ele pode ser salvo [...] A religião restringe esse jogo de escolha e de adaptação, desde que impõe igualmente a todos o seu próprio caminho para a aquisição de felicidade e da proteção contra o sofrimento.

Weber, entretanto, avança. Escreve que o desencantamento, na modernidade, implicaria o sentimento de não-plenitude das pessoas, que a morte e a vida do civilizado não têm sentido, pois o despojamento de significado faz da vida, também, um acontecimento sem significado. E a racionalização da vida, manifesta, sobretudo, no crescente processo de burocratização, estaria criando uma gaiola de aço, restringindo, progressivamente, a liberdade dos indivíduos, onde se banem da vida pública, cada vez mais, os valores supremos e mais sublimes. E lança respostas, porque conclui que "[...] tais valores encontram refúgio na transcendência da vida mística ou na fraternidade das relações diretas ou recíprocas entre indivíduos isolados" (Weber, 1992, p. 451). Anuncia, ademais, que "A ciência não tem sentido porque não responde à nossa pergunta, à única pergunta importante para nós: o que devemos fazer e como devemos viver" (ibid., p. 443). Assim, Weber afirmava, há um século, o declínio da religião e a permanência da religiosidade privatizada na busca humana de atribuição de sentido.

Em concordância com Negrão (2008), o movimento contrário à religião institucionalizada, sacramental, formadora de habitus religioso (cujo modelo é a Igreja Católica) é a construção de religiosidades individualizadas, ancorada, na maioria dos casos, em uma bricolagem própria do adepto ou do leigo, não do membro de 
uma igreja ou seita. Portanto, esse aparente labirinto sugere muitas questões, das quais serão destacadas algumas.

Quais são os principais elementos das religiões históricas ou tradicionais que são apropriados e quais os efetivamente "novos" nestes novos construtos?

Em que medida outros corpos teóricos (doutrinas, teologias) oferecem elementos-chave de maior poder interpretativo do que os da Sociologia da Religião clássica para explicar essa dinâmica?

ComoestásendoarquitetadaarepresentaçãodoOutro,namedida em que a ênfase passa a ser posta no indivíduo (autoconhecimento, autodesenvolvimento) e as dimensões de caridade, piedade vão sendo consideradas secundárias? E a importância da religiosidade para a relação "fundante" da Sociologia: a relação indivíduo-sociedade? Como refletir o papel das instituições no que toca à orientação e à proteção comportamental? Afinal, lembrando a tradição sociológica, se as instituições são capazes de atribuir sentido à ação dos indivíduos para sua vida social, seu comportamento, sua conduta, elas têm mais condições de sobrevivência. As muitas instituições religiosas sempre cumpriram essa função, em maior ou menor grau.

Finalmente, apesar de essa religiosidade no plural, dúplice, múltipla, lembrar superficialidade, mercado, inconsistência, está-se diante de um dos fenômenos mais significativos da atualidade: passagem de religião para religiosidade, ou religiosidades, no plural. Assim, essa religiosidade parece estar assentada, ela mesma, no pluralismo cultural da modernidade. Pluralismo que possibilitaria, para o indivíduo, uma contínua exploração de sentido. As crenças e as práticas religiosas passam a ser cada vez mais transitórias, provisórias e fluidas, não respondendo mais às diretrizes de uma instituição religiosa, ainda que recuperem elementos fundamentais das tradições religiosas, urdindo novas tramas: 
trajetórias do sagrado, ou reinventando o antigo e urdindo o novo, como diria Negrão.

\section{Notas}

1 O conceito mais próximo encontrado na literatura específica seria o de seita, mas a maioria não se caracteriza como tal. Dentre outras propriedades do objeto está o fato de não se tratar, propriamente, de conversão e de "membresia", daí a pesquisa intitular-se Sociologia das Adesões.

2 De fato, os dados do Censo Demográfico de 2000 indicam o surgimento de cerca de 1.200 novas denominações no país, sendo entre $60 \%$ e $70 \%$ de orientação pentecostal (Benedito, 2003).

The Western religious labyrinth. From religion to spirituality.

From the institutional to the non-conventional

Abstract: This article retrieves classic questions of the Sociology of Religion such as society's supremacy, social cohesion, moral forces, membership, rationalized and intellectualized modernity, alienation, and illusion to reflect the contemporary religious labyrinth. This begins mainly with the search for a non-conventional religiosity, a pluralistic religious field, transit, bricolage, privatization and individualization, spirituality and environmentalism, spirituality in the organizational context, the "entrepeneurshipping" of the churches and the spiritualization of companies, stressing a general tendency towards "spirituality yes, religion no".

Key words: religion; religiosity; spirituality.

\section{Referências}

ASHAR, H.; LANE-MAHER, M. Success and spirituality in the new business paradigm. Journal of Management Inquiry, Boston, 13(3), p. 249-260, 2004. 
ASHFORTH, B. E.; PRATT, M. G. Institutionalized spirituality. An oxymoron? In: GIACALONE, R. A.; JURKIEWICZ, C. L. (Orgs.). Handbook of workplace spirituality and organizational performance. New York: Harper \& Row, 2003.

BELL, E.; TAYLOR, S. A exaltação do trabalho: o poder pastoral e a ética do trabalho na nova era. Revista de Administração de Empresas, São Paulo, 44(2), p. 64-78, 2004.

BENEDITO, Júlio C. Emi Padê! Magia, conflito religioso e simbiose ritualística no Brasil contemporâneo. 2003. Tese (Doutorado em Sociologia) - Universidade de Brasília, Brasília.

BERGER, P. O dossel sagrado: elementos para uma teoria sociológica da religião. São Paulo: Paulus, 1985.

. Rumor de anjos: a sociedade moderna e a redescoberta do sobrenatural. Petrópolis: Vozes, 1996.

BERTHOUZOZ, R. Economic efficiency, ethical foundations, and spiritual values in the management of organizations. In: PAUCHANT, T. (Org.). Ethics and spirituality at work: hopes and pitfalls of the search for meaning in organizations. Westport: Quorum, 2002.

BETTO, Frei. Física, cosmologia, teologia e espiritualidade. Fragmentos de Cultura, Goiânia, v. 11, n. 6, nov./dez. 2001.

BONFATTI, P. A expressão popular do sagrado: uma análise psicoantropológica da Igreja Universal do Reino de Deus. São Paulo: Paulinas, 2000.

BOURDIEU, P. Gênese e estrutura do campo religioso. In: . A economia das trocas simbólicas. São Paulo: Perspectiva, 1974.

BRAUN, R. Desenvolvimento ao ponto sustentável: novos paradigmas ambientais. Petrópolis: Vozes, 2001.

BURITY, J. A. Mídia e religião: regimes do real entre o mistério, o aparente e o virtual. Revista Religião e Sociedade, Rio de Janeiro, 23(2), p. 77-91, 2003. 
CAMURÇA, M. As sombras na catedral: a influência New Age na Igreja Católica e o holismo da teologia de Leonardo Boff e Frei Betto. Numem. Revista de Estudos e Pesquisa da Religião, Juiz de Fora, v. 1, n. 1, 1998.

CAVANAGH, G. F. Spirituality for managers: context and critique. Journal of Organizational Change Management, New York, 12(3), p. 186-199, 1999.

CSIKSZENTMIHALYI, M. Flow: the psychology of optimal experience. New York: Harper \& Row, 1991.

DURKHEIM, E. As formas elementares de vida religiosa. São Paulo: Paulinas, 1989.

EHLERS, E. Agricultura sustentável: origens e perspectivas de um novo paradigma. São Paulo: Livros da Terra, 1996.

ENGELS, F. Literatura dos emigrados. In: MARX, K.; Sobre a religião. 2. ed. Lisboa: Ed. 70, 1976.

EVANS-PRITCHARD. A religião e os antropólogos. Revista Religião e Sociedade, Rio de Janeiro, 13(1), mar. 1986.

FERNANDES, Silvia R. A. (Org.). Mudança de religião no Brasil: desvendando sentidos e motivações. São Paulo: Palavra e Prece, 2006. (Coleção Ceris.)

FONSECA, A. Brasil. Fé na tela: características e ênfases de duas estratégias evangélicas na televisão. Revista Religião e Sociedade, Rio de Janeiro, 23(2), p. 33-52, 2003.

FOX, M. The reinvention of work. New York: Harper San Francisco, 1994.

FREUD, S. Obras Completas. Rio de Janeiro: Edição Standard Brasileira das Obras Psicológicas Completas de S. Freud, 1974.

GIACALONE, R. A.; JURKIEWICZ, C. L. (Orgs.). Handbook of workplace spirituality and organizational performance. New York: Harper \& Row, 2003. 
GIUMBELLI, E. O fim da religião?: dilemas da liberdade religiosa no Brasil e na França. São Paulo: Attar, 2002.

GUATARRI, Felix. As três ecologias. São Paulo: Papirus, 1990.

GUERRA, L. Mercado religioso no Brasil: competição, demanda e a dinâmica da esfera religiosa. João Pessoa: Idéia, 2003.

HERVIEU-LÉGER, D. O peregrino e o convertido: a religião em movimento. Lisboa: Gradiva, 2005.

HILL, P. C.; PARGAMENT, K. I. Advances in the conceptualization and measurement of religion and spirituality. American Psychologist, Boston, 58(1), p. 64-74, 2003.

HOLMGREN, D. Permaculture: principles and pathways beyond sustainability. Sidney: Holmgren Design Services, 2002.

HORTAL, J. A igreja e os novos grupos religiosos. Estudos da CNBB, São Paulo, n. 68, 1993.

JAMES, E. O. Historia de las religiones. Madrid: Alianza, 1994.

KING, U. Spirituality. In: HINNELS, J. (Org.). A new handbook of living religions. London: Penguin, 1997, p. 34-68.

KINJERSKI, V. Exploring spirit at work: the interconnectedness of personality, personal actions, organizational features, and the paths to spirit at work. 2004. Tese (Doutorado em Ecologia Humana) - Universidade de Alberta, Canadá.

LIMA, R. Barbosa de. Nova consciência religiosa e ambientalismo. In: SIQUEIRA, D.; de. Sociologia das adesões: novas religiosidades e a busca místico-esotérica na capital do Brasil. Rio de Janeiro: Garamond; Goiânia: Vieira, 2003.

MARIANO, R. Neopentecostais: sociologia do novo pentecostalismo no Brasil. Rio de Janeiro: Loyola, 1999.

MARX, K. Crítica da filosofia do direito de Hegel (1843-1844). In: ; ENGELS, F. Sobre a religião. 2. ed. Lisboa: Ed. 70, 1976 b. 
MARX, K. Gazeta de Colônia, Editorial do n. 179. In: ; ENGELS, F. Sobre a religião. 2. ed. Lisboa: Ed. 70, 1976.

O comunismo e "O observador renano". In:

ENGELS, F. Sobre a religião. 2. ed. Lisboa: Ed. 70, 1976c. (Escrito em 1847.)

. Teses sobre Feuerbach. In: ; ENGELS, F. Sobre a religião. 2. ed. Lisboa: Ed. 70, 1976a. (Escrito em 1845 e publicado pela primeira vez em 1888.)

McCORMICK, J. Rumo ao paraíso: a história do movimento ambientalista. Rio de Janeiro: Relume-Dumará, 1992.

MEDRADO, Maria. Do urbano ao rural: um estudo sobre a relação entre "nativos", os de "fora" e o movimento alternativo no Vale do Capão-Bahia. 2008. Dissertação (Mestrado em Sociologia) - Universidade de Brasília, Brasília.

MILLIMAN, J.; CZAPLEWISKI, A. J.; FERGUSON, J. Workplace spirituality and employee work attitudes. Journal of Organizational Change Management, New York, 16(4), p. 426-447, 2003.

; FERGUSON, J.; TRICKETT, D.; CONDEMI, B. Spirit and community at Southwest Airlines: an investigation of a spiritual values-based model. Journal of Organizational Change Management, New York, 12(3), p. 221-233, 1999.

MITROFF, I. I.; DENTON, E. A. A spiritual audit of corporate America: a hard look at spirituality, religion and values in the workplace. San Francisco, CA: Jossey-Bass, 1999.

NASH, L.; McLENNAN, S. Igreja aos domingos, trabalho às segundas: o desafio da fusão de valores cristãos com a vida dos negócios. Rio de Janeiro: Qualymark, 2003.

NEGRÃO, L. N. Pluralismo e multiplicidades religiosas no Brasil contemporâneo. Revista Sociedade e Estado, Brasília, v. 23, n. 2, set./dez. 2008. 
NOTH, W. Semiótica da magia. Revista da USP - Dossiê Magia, São Paulo, n. 31, 1996.

NOVAES, R. Juventude, percepções e comportamentos: a religião faz diferença? In: . Retratos da juventude brasileira. São Paulo: Fundação Perseu Abramo, 2005.

ORO, A. P.; STEILL, C. A. (Orgs.). Globalização e religião. Petrópolis: Vozes, 1977.

PAUCHANT, T. Ethics, spirituality at work: hopes and pitfalls of the search for meaning in organizations. Westport: Quorum, 2002.

PIERUCCI, A. F. Secularização em Max Weber: da contemporânea serventia de voltarmos a acessar aquele velho sentido. Revista Brasileira de Ciências Sociais, São Paulo, 13(37), p. 12- 38, 1998.

RODRÍGUEZ, P. Dios nació mujer. Barcelona: Editorial B, 2000.

SCHWARTZ, S. H.; HUISMANS, S. Value priorities and religiosity in four western religions. Social Psychology Quarterly, New York, 58(2), p. 88-107, 1995.

SIEPIERSKI, C. T. De bem com a vida: o sagrado num contexto em transformação. Um estudo sobre a Igreja Renascer em Cristo e a presença evangélica na sociedade brasileira contemporânea. 2001. Tese (Doutorado em Antropologia Social) - Universidade de São Paulo, São Paulo.

SILVA, R. R. Profissão pastor: prazer e sofrimento. Uma análise psicodinâmica do trabalho de líderes religiosos neopentecostais e tradicionais. 2004. Dissertação (Mestrado em Psicologia) - Universidade de Brasília, Brasília.

SIQUEIRA, D. As novas religiosidades no Ocidente: Brasília, cidade mística. Brasília: UnB, 2003.

. Fé e negócios, uma delicada relação. Indústria Brasileira - Revista da Confederação Nacional da Indústria, São Paulo, ano 3, n. 33, nov. 2003a. 
SIQUEIRA, D.; BANDEIRA, L.; RIBEIRO, P.; OSÓRIO, R. Carisma e narcisismo: as lideranças das novas religiosidades. In: COELHO, M. F. P.; BANDEIRA, L.; MENEZES, M. L. (Orgs.). Política, ciência e cultura em Max Weber. Brasília: UnB, 2000.

; LIMA, R. B. de. Sociologia das adesões: novas religiosidades e a busca místico-esotérica na capital do Brasil. Rio de Janeiro: Garamond; Goiânia: Vieira, 2003.

SOARES, G. B. O biopoder na contemporaneidade: o espírito do corpo e a alternativa budista. 2004. Tese (Doutorado em Psicologia) - Universidade Estadal do Rio de Janeiro, Rio de Janeiro.

SOARES, L. E. Religioso por natureza: cultura alternativa e misticismo ecológico no Brasil. In: . O rigor da indisciplina. Rio de Janeiro: Relume-Dumará, 1994.

UNGER, N. M. Fundamentos filosóficos do movimento ecológico. São Paulo: Loyola, 1991.

VALLE-HOLLINGER, A.; SIQUEIRA, D.; HOLLINGER, F. Religião e esoterismo entre estudantes: um estudo comparado internacional. Religião e Sociedade, Rio de Janeiro, v. 22, n. 2, 2002.

WEBER, M. A ciência como vocação. In: . Metodologia das ciências sociais. v. 2. Campinas: Unicamp; São Paulo: Cortez, 1992. . Economia e sociedade. v. 2. Brasília: UnB, 1999. 